\title{
sciendo
}

\section{MOTIVATION AND PREFERENCES OF HUMAN RESOURCES IN THE MEDICAL FIELD - PREMISES FOR FURTHER POLICIES IN THE MEDICAL SECTOR IN ROMANIA}

\author{
MIRELA CRISTINA GEORGESCU ${ }^{1}$, FLORENTINA LIGIA FURTUNESCU ${ }^{2}$, OTILIA \\ FRUMUSACHI $^{3}$, LAVINIA LOPATICA ${ }^{4}$, DANA GALIETA MINC $\breve{~}^{5}$ \\ 1,2,3,4,5 "Carol Davila" University of Medicine and Pharmacy, Bucharest
}

Keywords: discrimination, Romanian physicians, demographics

\begin{abstract}
The health professionals might be driven by different reasons in choosing their future medical specialty like passion, personal interest, balance with the family life, financial expectation, prestige etc. Our study aimed to explore the dominant preferences of the medical students in choosing their medical specialty in relation to their personal profile. We analysed the options of 3424 students from three cohorts the biggest public medical university of Romania. We found that most of the medical student are very career oriented, with low interest in having a family or children during their student life, most are income-dependent by others, and driven by passion/interest in choosing their future specialty, but with low interest for family medicine. Our data could be relevant for the policy makers for tailoring the longterm human resources polices adapted to the students' values, with the aim to assure an equitable coverage with medical services all over the country.
\end{abstract}

\section{INTRODUCTION}

When enrolling in a medical study program, a future student will mainly be interested in being accepted with the goal to be able to study and work in this field. If the positive, rewarding part of the medical profession (like reputation, prestige, social recognition etc) might have a weight in the students' decision, most of them won't probably take into consideration their future path and the effort that should be allocated (e.g. how many hours of study and/or work are needed daily, if they want a family or to study abroad, how easy is to change the working field).

Once accepted and after a period of studying, the students will begin to think about their future and will decide on what choices to make for their own good. There are a variety of experiences during their study years that influence these choices, and each one of them has roots in their unique characteristics that define them as individuals.

Most of the students will probably be guided further in life by their personal interests and expectations (1-3) and of course this is understandable, as every individual hopes to live his dream life and to try to achieve his personal goals like being starting a family, devoting one's entire spare time to study or being able to follow a certain hobby outside of working hours. Another strong influence was previous positive clerkship experience (3) and that is understandable since having a teacher or a mentor that has a number of qualities like being respectful, being well intentioned and actually wanting to teach another eager student the art of medicine, is mainly the base from where the student can start growing.

Evidence suggests that freshman students were influenced by personal perspectives such as confidence, attitude towards patients, while for senior year students their life was priming: lifestyle, free time vs. work hours. $(4,5)$

If the choice for the basic medical training is usually driven by the mentioned pros and cons, the choice of the medical specialty seems to be more influenced by the students' lifestyle $(4,6)$, their "personal interests", "previous positive experience", "personal reasons" and "job opportunities", while "influence from a mentor," "financial rewards" and "geographical location" do not have a very significant importance.(7)

Gender was supposedly the main factor influencing the choice of specialty, while many women preferred gynecology and men leaned towards surgery.(4) It has been noticed also that a student's propensity to primary care is strongly linked to him/her interest for becoming a general practitioner resident.(3,8,9) Some studies suggest that most of the students choose medical specialties that are in line with their capabilities, or are perceived as innovative, meanwhile the advice from family or friends seemed to have a lower influence.(10)

No matter what type of reasons drive the choice of the medical career and medical specialty, these should be known and understood by the policy planners and academic sector, in order to develop adequate programs and of adequate capacity to train enough medical professionals for the functioning the health systems. $(11,12)$ This issue is even more important in the developing countries, which are facing the emigration of their trainees.(13)

\section{AIM}

Our study aimed to explore the dominant preferences of the medical students in choosing their medical specialty in relation to their personal profile.

\section{MATERIALS AND METHODS}

Our study is descriptive and includes three cohorts of students of the University of Medicine and Pharmacy "Carol Davila" from Bucharest, Romania, the biggest public university

'Corresponding author: Mirela Cristina Georgescu, B-dul. Eroii Sanitari, Nr. 8, București, România, E-mail: mirela.georgescu@umfcd.ro, Phone: $+40722113112$

Article received on 20.04.2021 and accepted for publication on 04.06.2021 


\section{PUBLIC HEALTH AND MANAGEMENT}

of medicine from the country, with a very prestigious tradition of more than 160 years and with an annual enrolment exceeding 1000 students.

We included in our study the programs of Medicine (Romanian), Dentistry and Pharmacy.

We elaborated a questionnaire with three sections: one referring to the personal profile of the students, including some personal dimensions like marriage, income and aspirations related to their family, the second referring to medical specialty they intend to follow and the third related to intention to leave the country for various purposes.

We have used the national reference for classifying the specialty in main groups: surgical, medical (with individual approach of the family medicine which is the basis for the primary care coverage all over the country) and paraclinic (i.e. public health, epidemiology, laboratory, radiology, morphopathology and forensic medicine).(14) This was possible only for medicine, because the specialties for dental medicine and pharmacy are not grouped by the national reference. We applied the questionnaire among three consecutive cohorts of undergraduates (years 2016- 2018), after they defending their graduation thesis. We used the institutional e-mail addresses, we communicated very clearly the aim of the study and we required the support of the students' association. The overall response rate was of $87 \%$, meaning 3424 medical students, among which: 2221 studying medicine (778 in 2016, 799 in 2017, 644 in 2018); 658 dentistry (219 in 2016, 193 in 2017, 246 in 2018) and 545 pharmacy students (198 in 2016, 150 in 2017, 197 in 2016).

We have used descriptive statistic techniques. The scale variables were analysed as type of distribution, central tendency (mean or median) and dispersion. The qualitative variables were expressed as proportions. Comparisons were made using the Chi square test.

\section{RESULTS}

Our students had a median age of 25 years, similar by profile, except for pharmacy where median age was 24 years. This fact is explained by the fact that the pharmaceutical profile has 5 years of study meanwhile medicine and dentistry have 6 years. However, the age of the students varied among wide limits for all profiles, with maximum age at graduation reaching 47 years, 51 years and 41 years for the Medicine, Pharmacy and Dentistry respectively. Age-distribution is shown in figure no. 1.

Figure no. 1. Age distributions per profile

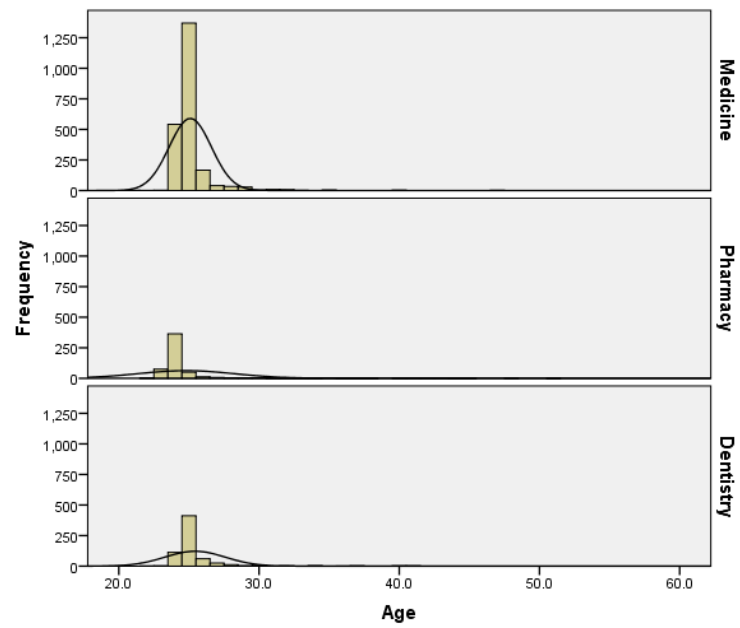

These advanced ages support the attractiveness of the medical field among the other university profiles, possibly because the career path is more predictable or the job opportunities are more numerous or easier accessible. These reasons are conducting a number of graduates of other profiles to follow the second university program in the medical field.

The gender structure was clearly in favour of females, that were predominant in each of the profile of study. Overall, $74.3 \%$ of students were females, with quite comparable proportions for medicine and pharmacy $(72.6 \%$ and $87.5 \%$, respectively, $\mathrm{p}=0.085$, Chi squared test) and a significantly lower proportion in dentistry $(69.1 \%, \mathrm{p}<0.001$, Chi square test).

Most of the students $(91.9 \%)$ are not married and do not have children (97.5\%). From the student's point of view, marriage can affect the studies and the future career. Also, combining family responsibilities and university obligations can lead to stress and can be a real challenge to their academic studies and in turn performance. For mostly the same reason as the absence of marriage - lack of time, insufficient money, stressful life - most of them are childless yet.

Another important aspect that influences the life of the students is, as we expect, the income.

Overall, $83.4 \%$ do not have an independent income and this characteristic is mostly valid for the students for Medicine (92.3\%) and Dentistry (90.6\%), meanwhile only $38.7 \%$ of the students from Pharmacy are still dependent, the rest having already a paid job. Despite the fact that medical studies are somewhat expensive, it appears that most of the students are extremely busy studying and so their time for gaining an additional income is limited.

When it comes to choosing a group of specialty, most of the students seem to be attracted by the medical specialties, but what is of concern is the very low proportion of students willing to follow the family medicine (figure no. 2). The specialties for dentistry and pharmacy are not classified in groups.

Figure no. 2. Students' preferences for groups of specialties (Medicine)

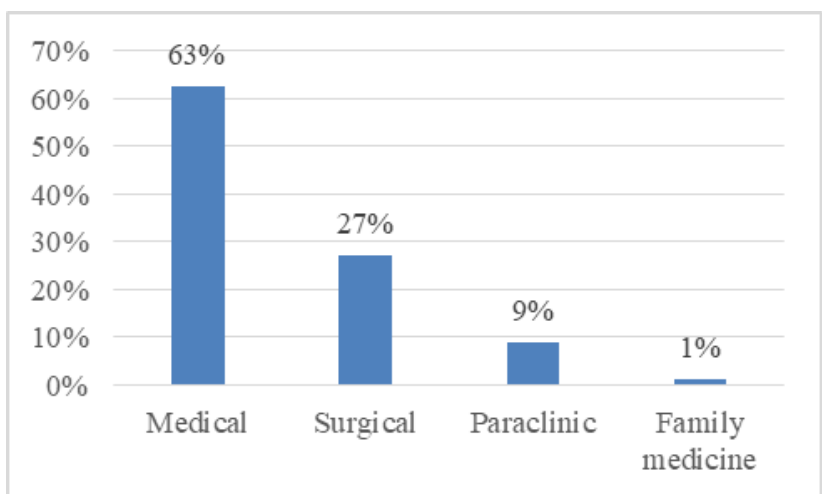

The top five specialties preferred by the Medicine graduates were the following: Cardiology - 7\%, Surgery - 7\%, Paediatrics - 6\%, Endocrinology - 6\%, Internal medicine - 6\%. In case of dentistry students, the top five choices were Endodontics - 12\%, Surgery - dento-alveolar - 12\%, Prosthetics $-12 \%$, Periodontology $-14 \%$, Orthodontics $-27 \%$. On the other hand, pharmacology students have fewer possibilities when choosing their specialty. Due to that, half of them chose to become a Pharmacist (52\%), while the other half (40\%) chose Clinical Pharmacy.

The main declared reason for a certain preferred specialty was the passion/attractiveness for the specialty itself for the wide majority of students $(84.6 \%)$, followed at big lag by working program $(7.6 \%)$ and financial perspectives $(6.3 \%)$. The 


\section{PUBLIC HEALTH AND MANAGEMENT}

duration of the speciality seems to have a very limited importance in decision for most of the students (figure no. 3).

Figure no. 3. Students' dominant reason for choosing the specialty



The same distribution of the reasons was seen in all specialty groups, for medicine, with the exception of the family medicine, where the working program was the dominant reason for half of the students. In the Pharmacy and Dentistry fields passion was also the dominant reason $(85 \%$ and $84 \%$ of the students respectively), followed by financial argument (11\% and $7 \%$ respectively), and working program. The duration of the specialty was, again, important for a very limited number of students in both fields (1\% and 3\% respectively).

\section{DISCUSSIONS}

Our study revealed that most of the medical students do chose their specialty as a result of their passion or interest in the specific field. This is the dominant reason for students from medicine, dentistry and pharmacy as well, and it is followed, at big distance, by the working program and the financial expectations related to the future career. A slight preference in favour of the financial dimension was found in students from pharmacy and dentistry, and, as well in the surgical specialties group from medicine.

One important concern is related to the limited preference for family medicine, as speciality oriented more to the community, and with probability of practice in either urban or rural areas, but outside of the hospital.

The family medicine is the basis of the health system, which is social insurance based, and around $20 \%$ of the specialized physicians working at present in the country are family doctors.(15) In Romania $46 \%$ of the total population still live in rural areas and $40 \%$ of the about 10000 family doctors are working there, this being the only available medical doctor [16]. So, there is a must to keep the coverage with family doctors in the country, with focus for the rural areas, for assuring an equitable coverage of the entire population with primary care services. This goal is in line with the Alma Ata Declaration for primary care, and the Sustainable Development Agenda 2030, supporting the principle of leaving no-one behind. $(17,18)$ If the new generations are not attracted of this specialty, this is an important trigger for defining new policies aiming to increase motivation of the students to apply also for family medicine. These policies should address the whole country, but with focus on rural and disadvantaged areas.

Another important lesson to learn is that wide majority of the students are not married and do not have children yet, being very oriented on their studies. Indeed, the median age is 25 years, they are still young but maybe more flexible alternatives to combine the study and the family life could be considered for the university in the future.

One possible limitation of our research is the fact that we performed the study using the university's network and infrastructure - like the institutional address. There is a possibility for the students to give the "expected" or "politically correct" answers related to their drivers in choosing the speciality. However, we tried our best to minimize the risk of bias, by explaining very clearly the goal of the study and by asking the support of the students' association.

Another limitation is that we addressed only the students from one university and thus the data cannot be generalized.

\section{CONCLUSIONS}

Most of the medical student in Romania are very career oriented, with low interest in having a family or children during their student life, and most are income-dependent by others. They are generally driven by passion/interest in choosing their future specialty and their interest for family medicine is rather limited. This is a trigger for the policy makers to adapt the long-term human resources polices with the aim to assure an equitable coverage with family doctors all over the country.

\section{REFERENCES}

1. Rosser WW. The decline of family medicine as a career choice. CMAJ 2002;166:1419-1420.

2. Sullivan P. Family medicine in crisis? CMAJ 2003;168:881-882.

3. Hin Hin Ko, MD, Tim K. Lee, PhD, Yvette Leung, MD, Bruce Fleming, MD, Elena Vikis, MD,, Eric M. Yoshida, OBC, MD, MHSc, FRCPC. Factors influencing career choices made by medical students, residents, and practising physicians. BCMJ. 2007;49(9):482-489.

4. Levaillant M, Levaillant L, Lerolle N, Vallet B, HamelBroza JF. Factors influencing medical students' choice of specialization: A gender based systematic review. E Clinical Medicine, Volume 28, 2020, 100589, ISSN 25895370, https://doi.org/10.1016/j.eclinm.2020.100589.

5. Soethout M.B.M. ten Cate ThJ van der Wal G. Factors associated with the nature, timing and stability of the specialty career choices of recently graduated doctors in European countries, a literature review. Med Educ Online. 2004 Dec;9 4360.

6. Matteson MT, Smith SV. Selection of medical specialties: preferences versus choices. J Med Educ. 1977 Jul; 52:548 554.

7. Hin Hin Ko, MD, Tim K. Lee, PhD, Yvette Leung, MD, Bruce Fleming, MD, Elena Vikis, MD,, Eric M. Yoshida, OBC, MD, MHSc, FRCPC. Factors influencing career choices made by medical students, residents, and practising physicians. BCMJ. 2007;49(9):482-489.

8. Rabinowitz HK, Paynter NP. The role of the medical school in rural graduate medical education: Pipeline or control value. J Rural Health 2000;16:249-253.

9. Pathman DE, Steiner BD, Jones BD, et al. Preparing and retaining rural physicians through medical education. Acad Med 2002;77:475-480.

10. Salman Y. Guraya, Hamdi H. Almaramhy. Mapping the factors that influence the career specialty preferences by the undergraduate medical students. Saudi Journal of Biological Sciences. 2018;25(6):1096-1101, ISSN 1319562X, https://doi.org/10.1016/j.sjbs.2017.03.019.

11. World Health Organization. The WHO Global Code of Practice on the International Recruitment of Health Personnel. Geneva, 2010.

12. Wismar M, Maier CB, Glinos IA, Dussault G, Figueras J. Health professional mobility and health systems. Evidence 


\section{PUBLIC HEALTH AND MANAGEMENT}

from 17 European countries. WHO European Observatory on Health Systems and Policies. 2011;1:632. http://apps.who.int/iris/bitstream/10665/170421/1/HealthProfessional-Mobility-Health-Systems.pdf.

13. OECD. International migration outlook 2015, OECD Publishing,

Paris.2015. http://dx.doi.org/10.1787/migr_outlook-2015-en,

14. Order of the Minister of Health no 1509/2008 on the approval of the Nomenclature of medical, medico-dental and pharmaceutical specialties for the healthcare network, with subsequent amendments.

15. National Institute of Statistics. Tempo on-line database http://statistici.insse.ro:8077/tempoonline/\#/pages/tables/insse-table

16. Vlãdescu C, Scîntee SG, Olsavszky V, HernándezQuevedo C, Sagan A. Romania: Health system review. Health Systems in Transition. 2016;18(4):1-170.

17. World Health Organization. Declaration of Alma-Ata International Conference on Primary Health Care, 6-12 September 1978 https://www.who.int/publications/almaata_declaration_en.p df

18. United Nations. The 2030 Agenda for Sustainable Development. https://sdgs.un.org/goals. 